\title{
Educating Girls: Complexities of Informing Meaningful Social Change
}

\author{
KAREN MONKMAN \\ DePaul University, USA
}

\begin{abstract}
Jackie Kirk devoted her career to trying to bridge the relationships among research, policy and practice for the purpose of making the world a better place for children, teachers, and communities. Reflecting her priorities, we examine herein how research, policy and practice interact to enable a robust and dynamic program that educates girls for purposes far beyond typical policy priorities of access and parity. To do so, we rely on interviews and focus group discussions that involved over 130 individuals who were involved with one girls' education program in a remote region of a Southeast Asian country. Their narratives reveal that the program was flexible and responsive, yet guided by clear ideas about gender equity. This work is not prescriptive or predictable; it evolves through dynamic interactions. Global policy priorities of access and parity became means toward more important goals including community sustainability in the face of environmental and economic challenges. Structures that enabled this robust program included space, time, funding, and a dynamic conceptual lens.
\end{abstract}

KEYWORDS gender equity; girls' education; education policy; development education policy, global education policy

\section{Introduction}

Jackie Kirk devoted her career to trying to bridge the relationships among research, policy and practice for the purpose of making the world a better place for children, teachers, and communities. She worked with development organizations to improve educational experience while paying attention to gender inequities. She informed this work with solid research on the nuances and complexities of lived realities in particular locations and times (e.g., Kirk, 2004, 2007; Kirk \& Sommer, 2006). This balancing of commitments continues for many of us who want policy agendas to better reflect the priorities of people who are the intended beneficiaries of global education and development projects and programs while also taking into account social 
structures that perpetuate inequities. This article was inspired by ongoing conversations with Jackie Kirk during the 2000 s, as we collectively sought to deepen the meaningfulness of work we do in education.

In this article we examine how research, policy and practice interact to enable a robust and dynamic program in Southeast Asia that educates girls for purposes far beyond typical policy priorities of access and parity that have dominated international policy and programming. We focus on one girls' education program in Southeast Asia that moved beyond the access and parity goals for girls' education. This program - the story of which is told in this article - was not prescriptive or predictive; it evolved through dynamic interactions over time. Structures that enabled this robust program include space, time, funding, and a dynamic conceptual lens.

\section{Conceptual Grounding}

This research is situated in two primary conceptual realms - one that focuses on the interactions among research, policy and practice, and the other that is particular to gender and education, with a specific focus on girls' education.

\section{Research, Policy and Practice}

The integral relationship of policy, research, and practice is thought to have synergistic potential in strengthening educational work (Levinson, Sutton, \& Winstead, 2009), yet we continue to see more autonomous approaches to each, as neoliberal agendas strengthen their influences. Global education policy makes assertions that schooling will solve complex social problems (Kendall, 2007), while devoting increasing energy instead to measuring outcomes and accountability concerns (Monkman \& Hoffman, 2013). Practitioners and organizations are pressured to demonstrate impact, often narrowly defined, to justify their programs and projects; furthermore, research, especially qualitative research, is thought by some as irrelevant to the applied concerns of policy and practice, yet it is through research that we can understand more complex dynamics. Without integral dialogue among these three domains in international development education, efforts are likely to fall short of their potential. Many of us - Jackie Kirk included - have sought to engage in international education work in ways that bridge this divide, by doing research to strategically inform policy and practice; by generating or influencing policy so it can support worthwhile educational improvement; and by engaging in practice to create meaningful and impactful experiences for girls and boys, women and men, teachers and administrators, and local communities, and to inform policy and motivate research.

While synergistic interactions among practitioners, policy makers and researchers are important in overcoming those siloed domains, divergent 
conceptual frames and ideological orientations also point us in different directions. Human rights as a policy frame, for example, in education and development policy and practice has been taken on by many organizations (including UNICEF, Oxfam, CARE, and others), in part to counteract the human capital orientation of development in earlier decades (and still by the World Bank). Human rights shifts our focus to people's lives, and to education as a right (as opposed to education as a vehicle to getting jobs or for economic development). How human rights is conceptualized in policy varies, and so there are different approaches to it; in addition, there can be tensions or resistance in practice (Bajaj, 2011; Coysh, 2014; Zembylas, 2017). Also, human rights and gender empowerment are sometimes used as partially overlapping concepts that are synergistic yet difficult to disentangle, as is the case in this program and our research.

With respect to girls' education, Unterhalter, Heslop and Mamedu (2013) identify two trends - one that conceptualizes gender disparities as a question of distribution inequalities, and another that points to structural inequalities that constrain capabilities. The first seeks to get more children into school (and sometimes to improve quality of the educational experience), and the second prioritizes deeper social structural change that would not only increase access and parity but also alter relations of power so that changes are deeply grounded and sustainable. The first is more prevalent in policy, practice, and assessments, although it is the second that has more dynamic potential for long-term change and is often the focus in academic research.

Embedded in these perspectives one can also see divergent conceptualizations about gender and education, in which sex is conflated with gender, and schooling with education (McCormick, 2016). Learning that takes place outside school and program settings is often ignored in initiatives informed by a distributive orientation, and knowledge gained from living life is devalued compared to school-based knowledge. Similarly gender, when it is conflated with sex, confuses biological categories of male and female (sex categories) with a more fluid and malleable understanding of gender as socially constructed (Lorber, 1994). This essentialist thinking precludes the more interesting and influential consideration of how the social construction of gender is embedded in assumptions about education (not merely schooling) for boys and girls, or women and men, and how education influences the meaning systems embedded in locally constructed gendered social relations. All people - not just girls and women - participate in the social construction of gender, so everyone needs to be involved in and committed to changes in how gender is socially constructed.

\section{Gender and Education as a Global Policy Priority}

Gender has become more prominent on global education and development policy platforms, spurred by Esther Boserup's (1970) analysis of gender and 
development, King and Hill's (1993) analysis of women and girls' education, and strengthened by the 1995 Women's Conference in Beijing (along with many other influential scholars, activists and movements; see for example, Kabeer, 1997; Mohanty, 2003; and overviews in Monkman \& Webster, 2015; Unterhalter \& North, 2011). Education for All (EFA) and the Millennium Development Goals (MDGs) then became the guiding policy forces for education globally; they included recognition of the education of girls as integral to broader development interests by making access and parity major goals. However, while they tried to push beyond access and gender parity, "the meanings of gender that were invoked remained limited" (Unterhalter \& North, 2011, p. 2), thereby narrowing the scope of girls' education initiatives. Enrollment rates (access) and gender parity are relatively easy to measure (counting bodies in seats). Global funding increased to support countries' progress toward meeting EFA goals and the MDGs which enabled more children to attend school. Girls' enrollment rates were increased, and parity has been reached in about two-thirds of the world's countries at the primary level (UNESCO, 2017). In some countries more girls than boys now attend schools, although the reasons are not always clear and are often not reflective of situations characterized by social justice. Sometimes they are left behind in school due to lack of opportunities outside school (Kendall \& Silver, 2014).

Reaching gender parity does not mean full enrollment of either girls or boys, despite progress made in the past couple of decades. By 2010, 61 million children of primary school age were still not in school, $53 \%$ of whom were girls (UNESCO, 2012; Lewis \& Lockheed, 2006). Some organizations shifted their focus to post-primary education, as the numbers of girls (and boys) in primary school increased (UNICEF/MWAI, 2007). In 2015, 264 million school-aged children were not in primary or secondary school; more alarmingly, 17 million children are unlikely to ever enroll in school (UNESCO, 2017). While gains have been made in increasing school enrollment overall, there is variation across regions and localities. Furthermore, getting girls into school does not necessarily mean they will remain, or even learn much (Chisamya, DeJaeghere, Kendall, \& Khan, 2012; UNESCO, 2018).

Beyond access and parity, more attention to quality has been increasingly advocated (Aikman \& Unterhalter, 2005; Herz \& Sperling, 2004; Sutton, 1998 ), yet progress has been uneven. In approaches that view distribution as the problem (Unterhalter, Heslop, \& Mamedu, 2013), what constitutes quality tends to be understood in ways that are easily measurable; this likely limits the ways that quality is conceptualized, thereby limiting strategies to improve it (Aikman, Unterhalter \& Challender, 2005). While gender has entered the development education policy priorities, the continuing focus on access and parity has prompted research on practices, strategies and other concerns that are relatively easy to measure (to reveal progress toward access and parity). At the same time, scholarly research on lived experience, material realities, and discursive framing of understandings has increased. We now turn to a 
more focused look at educating girls.

\section{Educating Girls}

Strategies commonly employed in girls' education programs in locations with very different histories, cultures, and conditions of life include stipends or bags of rice (to offset the direct and opportunity costs of attending school), activities designed to change how people think (e.g., convincing families to send girls to school), and life skills classes for young women (often to make up for limited formal education and to address assumed needs of adolescents). Some NGOs also build schools in communities to reduce commuting time and increase safety for girls in their commutes to school, while UNICEF and others advocate for "girl friendly" schools (Herz \& Sperling, 2004). While many of these strategies were initially recognized through research, and while such strategies can increase numbers of girls in schools, they are often perceived to be limited in scope, sociocultural relevance, sustainability, and in creating meaningful social change (Chisamya et al., 2012). Higher enrollment rates can be short-lived when other pressures subsequently take children out of school (Kendall, 2007). Pressure to scale up or uncritically borrow strategies from other programs can work against fitting strategies to local realities. A recent donor shift in accountability promotes payment for outcomes as a supposed motivator for producing results - the more girls who enroll in school the more money schools or NGOs receive (UNESCO, 2017). At its worst, this can put pressure on providers to seek quick outcomes, even if not lasting or meaningful. In addition, this dance between policy and practice (often driven by accountability pressures) largely ignores what we know about the contextualized experiences of children, families, and teachers.

Beyond the policy and practice domains, a different set of literature examines lived experience within the contexts of particular histories, cultures, sociopolitical and economic structures, and life conditions. These tend to be more qualitative in approach, less interested in solely measuring access and parity, and often revolve around community-defined or locally relevant concerns. A few examples reveal a wide range of complex issues and their structural underpinnings. Kendall and Silver (2014) reveal how EFA has created an elite discourse about education in Malawi which draws boys of means out of school into jobs, leaving poor girls behind, in school, with limited opportunities for their futures. Research focused primarily on access and parity (distributive inequalities) would miss questions about why and how (structural inequalities) and consequences of schooling. Vavrus (2002) unpacks various understandings of tradition in Tanzania and how they shape historical orientations toward gender and education, which in turn shape policies for girls' schooling. She also reveals how structural adjustment policies in Tanzania affect the lives of secondary students, particularly girls 
(Vavrus, 2005). Murphy-Graham (2008) focuses on complexities of secondary schooling in Honduras, showing how attending schooling does not automatically produce empowerment; this finding challenges policy assumptions that attending school results in empowerment. In India, the careful creation of a unique space for girls enabled an empowerment process to develop (Shah, 2011). Varying conceptualizations of empowerment (Monkman, 2011) reveal more nuanced understandings while complicating the concept's usefulness in policy and practice that seeks quick and easily measurable results.

Nuanced research has also been done with a focus on teachers, including women teachers' differential access to income relative to male teachers in Uganda, which diminishes their professional social status and the economic foundations for their personal lives (Molyneaux, 2011); juxtaposed with delayed payment of salaries, women teachers' lives are further constrained. The "impossible fictions" of women teachers in Karachi situates them in "a constant tension between possibility and impossibility" (Kirk, 2004, p. 379) due to the oppositional binaries that undergird notions of gender and work. The lives of teachers affect the learning experiences of their students, while also reinforcing or challenging gendered social structures. Research related to gender based violence is also notable (e.g., Kirk, 2007; Leach \& Mitchell, 2006; Parkes, 2016). While these are just a few examples, the point is that what we know from research of this type is much more nuanced than what is implied in global policy discourses (Monkman \& Hoffman, 2013; Kendall, 2007) or in narrow approaches to implementing policies.

\section{Methods}

This article relies primarily on data collected in 2015 during a program evaluation which was structured not as an impact study but as an opportunity to tell the story of the program. We collected data in six villages, by conducting 50 interviews and focus groups and involving 138 students, teachers, community members, policy makers, NGO staff and partners (see Table 1).

Most of the interviews and focus groups were audio-recorded and transcribed, but several took place in a setting where ambient noise levels were too loud for audible recordings (i.e., in a metal roofed building during heavy rain in one village). On this day we took notes by hand. Each interview lasted 30 to 60 minutes, with most lasting about 60 minutes. Each focus group, which involved two to 10 participants, lasted 60 to 100 minutes. Interpreters were used in the villages during data collection; often two interpreters were needed, one to interpret from local languages to the national language and another to English. Only the English translations in the recordings were transcribed, although the transcribers were fluent in the national language, so they could check the English translations as they 
transcribed. Names of individuals, villages, and organizations have been omitted for privacy reasons.

\begin{tabular}{|l|l|l|l|l|l|}
\hline & \multicolumn{3}{|c|}{$\begin{array}{c}\text { Number/Sex of } \\
\text { Participants }\end{array}$} & \multicolumn{2}{|c|}{$\begin{array}{c}\text { Number of Interviews } \\
\text { and Focus Groups } \\
\text { Conducted }\end{array}$} \\
\hline Participants & Female & Male & Total & Interviews & $\begin{array}{c}\text { Focus } \\
\text { Groups }\end{array}$ \\
\hline $\begin{array}{l}\text { NGO staff, consultants, and } \\
\text { partner institutions (e.g., } \\
\text { other NGOs and UNICEF) }\end{array}$ & 5 & 6 & 11 & 6 & 2 \\
\hline $\begin{array}{l}\text { Government officials at } \\
\text { national, provincial, district } \\
\text { and sub-district levels }\end{array}$ & 7 & 3 & 10 & 8 & 1 \\
\hline $\begin{array}{l}\text { Women's Committee } \\
\text { members }\end{array}$ & 15 & 0 & 15 & 0 & 3 \\
\hline $\begin{array}{l}\text { Parents, Grandparents, and } \\
\text { Village Elders }\end{array}$ & 9 & 16 & 25 & 2 & 3 \\
\hline Youth (Students) & 28 & 16 & 44 & 6 & 6 \\
\hline Teachers & 8 & 8 & 16 & 4 & 4 \\
\hline School Board members & 5 & 12 & 17 & 0 & 5 \\
\hline Total: & $\mathbf{7 7}$ & $\mathbf{6 1}$ & $\mathbf{1 3 8}$ & $\mathbf{2 6}$ & $\mathbf{2 4}$ \\
\hline
\end{tabular}

Table 1. Participants and Data Collection

Data were coded separately by two researchers, each in multiple rounds and with searches for negative cases. Analysis followed conventional qualitative methods which allow themes to bubble up from the data (Rossman $\&$ Rallis, 2003). Two themes that represent the core story of this program are educating girls and informing change. The third theme, infusing gender, emerged as a salient pattern across the other themes. These three thematic findings are presented below as Local Narratives, with analysis presented under the heading Meaningful Social Change through Education, where we focus on the conceptual ideas that emanate from the findings. First, however, we describe the context within which this program took place.

\section{Context}

This girls' education program grew out of the global priorities related to educating girls, and was funded with private donations to an international NGO. The funding source encouraged innovation, and the NGO built on their history of making gender a priority, which is grounded in empowerment and human rights frameworks.

The in-country staff included a few expatriates who have lived in the country for several years; a few locals who come from nearby indigenous communities; and other nationals, some of whom have been challenged to 
rethink their attitudes toward ethnic minorities. The indigenous communities in which the NGO works are in a remote area where most of the residents have low levels of educational attainment (if any), speak local languages, and engage in subsistence farming. Historically, political tensions and geographical isolation have created suspicion and prejudices between the national majority and indigenous groups.

Economic exploitation and environmental challenges are recent and severe, and have pushed subsistence farmers farther from villages to less fertile land, and destroyed much of the nearby forests. Like many very poor communities worldwide, there are few opportunities for paid employment in the villages, and often schools and health-related services are not nearby. The median age in this region is about five years younger than the country as a whole, and life expectancy is about 20 years less than the national average of about 60 . Internal migration is also increasing, with people from the dominant ethnic group moving into the region, now comprising about one-third of the population. The net school attendance rate in this remote province is $20-30$ percentage points lower than other provinces, hovering just above half the school age population, although this is also changing quickly.

The NGO's girls' education program was an integrated program whose primary goal was to increase access of ethnic minority children, particularly girls, to quality education. The girls' education components were integrated with multilingual education (MLE) in grades 1-3, and early childhood education (ECE). Both MLE and ECE attracted more girls and boys to the school initially, and helped children to transition to monolingual (national language) state schools. The NGO had also built community schools for the lower primary grades, and recruited local high school leavers and trained them as bilingual teachers. The NGO had previously been engaged in a host of specific development projects such as digging wells and building toilets in the same villages.

The NGO conducted extensive research in the communities prior to designing the girls' education program; this was possible due to the ten-year funding period. This research led to replacing some of their initial assumptions with more nuanced understandings (explained later) of why girls were not in school, how educating girls fits within local concerns, and how education of indigenous children (boys and girls) relates to social change writ large, and cultural beliefs, values and processes. This was a turning point. The NGO also engaged villages in creating or reinvigorating supportive structures for the community schools, including the local School Boards, to oversee budgets and teacher attendance, and village Women's Committees to actively engage with a broader range of gender-related issues. The NGO has also worked extensively and strategically with local, regional and national government entities, UNICEF, and other local and international NGOs, and has established dynamic working relationships, so much so that the national policies related to ECE and MLE have been informed by the NGO's successful work in this region. Several villagers had also taken on the 
language of human rights and women's rights, reflecting the NGO's orientation.

Through the building of intentional and meaningful relationships and a deepening understanding of local realities and concerns, and informed by flexible conceptual frameworks, the NGO staff and participants came to recognize and re-think gender relations, and to link girls and schooling with other important priorities including multilingual education and cultural pride. Educating girls in this program was not merely about meeting EFA goals and the MDGs, but became an integral part of a multi-faceted approach to community survival.

\section{Local Narratives}

Here we tell the story of this girls' education program in Southeast Asia, with an eye to understanding underlying local gendered structures and other complexities. We begin with how villagers articulate their rationale for educating girls; then move to the basis of enabling or informing change. Finally, we examine changes in gendered priorities integral to educating girls, namely, infusing gender into the discursive understandings, which in turn shape local policy and practice.

\section{Educating Girls}

A young woman School Board member gave the following reason for supporting the girls' education work of this NGO in her village:

I chose to do this work because I would like all the indigenous children, especially girls, to join school and get knowledge. This is because we need to avoid being cheated, and we need to be able to find work. In my experience, if we can't read or write, we are unable to do work or have a small business. (Village A, interview)

She went on, using a plant metaphor to highlight her role in supporting the process of change involving the next generation: "I am an older [reed] now, so it's my responsibility to encourage these new [reeds] to grow, to grow in education. My role is to encourage younger [reeds] to grow in school."

Members of one village's Women's Committee explained that previously, only boys went to school in their village, but more girls are in school now, due in part to the partnership work of the NGO and the Women's Committee. They realized that decreasing girls' workloads and educating parents about the importance of sending girls to school is important. They were proud to report that "in the village we have schools, teachers, and students learning" (Village $\mathrm{B}$, focus group). 
The initial vehicle for increasing enrollments in village schools included building community primary schools and developing MLE as the curricular base. Locally recruited teachers were trained and hired for jobs in the community schools, which created cultural cohesion among teachers, students, and the communities. The addition of ECE then served as a conduit to primary school by providing learning experiences to build on as children move on, and a daycare space for siblings of older children - typically girls' younger siblings - so they could continue their own schooling. The outcomes went far beyond access; even though access to schooling was an integral part, access was just the beginning. Narratives suggest that villagers became more engaged as active citizens, welcomed public discussions about gender and human rights and embraced a commitment to change behaviors related to domestic violence and sharing chores.

In one School Board focus group a discussion ensued about how the village has changed as more children attend school. In another village, a woman noted a connection between educational equality and access, and women's equality and quality of life in general:

I saw in my village ...- in the past when they woke up, [the children] just sat in front of the house. Nowadays when they get up, they clean their teeth, bodies, and get their bags for going to school.... In the past when we woke up, we just went to the farm. But nowadays when we wake up, we have a discussion with the men about what we are doing.... It has changed our life. We can make plans to discuss with each other. (Village B, Women's Committee focus group)

Young people, both boys and girls, described how their families were increasingly sharing work among their members. One girl captured the common perspective well:

[The NGO] is working to educate the elders in the community about sharing housework, to know about rights, and to send children to school. In my family, my parents are sharing the housework, like my father helps my mother. And for boys and girls, my younger brother helps me collect the water. (Village C, Girls'

Club focus group)

A boy described the change in his family in this way: "[We] can divide work with each other, ... not ... much work [is put] on only one person. [We] share the work together" (Village C, boys' focus group). Another girl explained how work was now distributed more evenly among siblings in her family:

My younger brother and sister study in the afternoon. I study in the morning. When I go to school, they do housework. When I come back, I do housework and they go to study. My parents want us to learn and want us to go to school, so they push us to go to school. (Village B, girls' focus group) 
Sharing household chores was mentioned by almost all participants, and reflects a major change in the gendered division of labor. The NGO had initially thought that life skills training for adolescent girls would be the main focus of their work in this program, but after learning more from the initial research they did about the communities' priorities and ways of living, they realized that girls, relative to boys, did not attend school due primarily to heavy work loads which left no time for school. Through discussing this in communities, villages decided to share work more equitably so that chores did not remain a deterrent to attending school for girls. Having a strong research base and a participatory process informed strategies and policy decisions, making the program more integral to how the villagers lived their lives and to their own communal priorities. Attending school was talked about by villagers not only as a right of girls, but as necessary to village survival.

Part of the NGO's framing of equality for girls was the grounding in a human rights paradigm, which they have worked actively to refine over time. This framing guides the NGO's work generally. They also shared it with, but did not impose it on, the communities. Their approach is one reflective of participatory action research, although they did not use that term; they introduced ideas and generated reflective discussion, while letting the communities take them up or not. While not everyone used the term, as we will see later, many villagers embraced this human rights perspective as it relates to educational access for girls, and also in areas beyond schooling. Domestic violence was named by many of the adults as something that has decreased as villagers increasingly recognized it as a human rights issue for women. The conceptual underpinnings, like the early research, served as a guide and a meaningful basis for social change. Furthermore, adequate time and space to authentically dialogue, and a deep trust of the NGO, likely facilitated acceptance and application of the concept of gender equality by the communities in supporting more equitable work loads, which increased school participation.

\section{Informing Change}

What, from the perspective of the villagers, motivated or influenced the changes? Community members described a combination of factors, including changing social norms (as suggested above) and technological advances that have led to decreased workloads and increasing gender equality in their villages. In the following quotes, three members of one School Board, who are also grandfathers and fathers of local schoolchildren, respond to a question of how life for girls in their village is different from life for girls when they were young boys: 
When I was young, girls had many tasks each day. [Girls] had to pound the rice by themselves before they could cook it - they had to leave home to collect water, wood, to look for vegetables - many, many tasks.

Now there are machines to help pound rice, for example, and men also carry firewood from the forest. But now a husband will bring firewood, especially by using motorbikes.

We didn't understand about advocacy for girls.

We didn't understand about domestic violence or equal rights between boys and girls and men and women.

And now we understand about how to reduce domestic violence. And we know about human rights, how other people have equal rights.

(Village A, School Board focus group)

Again, we see influence of a human rights orientation, as it applies to gender and recognition of human rights shaping how life is lived, from gender based violence to a gendered division of labor. When asked what kind of impact the re-distribution of workload had on men, one man responded:

We're very happy for the women, too - we understand that it was very difficult for women. They have to do many things, like have children and do a lot of hard work, look after animals, and prepare cooking for the family, and go to the forest.

So life was too hard for them. (Village A, School Board focus group)

We tried hard to get under the surface in the interviews and focus groups, knowing that it is often challenging to get privileged groups (men, in this case), to do more work or share responsibilities with others. Structures such as a gendered division of labor often situate men in social positions of unearned privilege (McIntosh, 2013). Challenging those structures can feel like a reduction of that advantage. Even though we asked men why they would want to share chores (as their work load would increase), their responses always pointed to the common good: sharing chores and enabling girls to attend school was best for the community. None of their responses focused on their experience as individuals.

Understanding the life experience of others is necessary for those advantaged by social structures - men and boys in this case - to become invested in change that benefits the whole community. Indeed, girls' education initiatives that solely target girls often have limited success, restricted by narrow policy targets and reflecting distribution priorities (e.g., increasing enrollments). It is the complex intertwining of societal processes that creates structures of inequities. Solutions must be equally complex if they are to be meaningful and sustainable. Men and boys must be part of changes in gendered social relations in order for changes to be structural. It 
would appear that a communal cultural orientation was key to facilitating this shift in thinking about chores and educating girls, as these were seen to benefit the whole community.

Another key influence in enabling change was making learning accessible through languages of instruction understood by villagers and recruiting and training locals as teachers, which made the community schools a valued and integrated part of the villages. When schooling is relevant and in a language children understand, they are more likely to like school, which reduces dropping out. A 14-year old girl explained: "I like going to school because the schools are good, and modern. I have classmates and friends who are good and kind - we are close. And my teachers are good at explaining and educating us" (Village D, interview). Wanting to go to school often relies on school providing a good experience. Improving quality requires more than using prepackaged curricula or learning new pedagogical strategies.

Infrastructural changes increase desires to attend school. Another 14-year old girl in Village B identified what the NGO has done in their community: "[They] build schools, they support children, support students' learning, and also they build toilets in the school and provide materials for our studies" (Village B, interview). She continues:

[The NGO] supports children to make them feel school is nice so they want to come to school. [The NGO] provided interesting materials for the children, the children want to go to school, and other children follow them to school because of the interesting material.

Indeed, we heard several stories of non-enrolled children, some too young for school, following school children to school because they were anxious to be part of what was happening in the classrooms.

Other children mentioned the wells dug by the NGO, which provided easier access to water, as another technology that made attending school easier. This, of course, relates to household chores as the location of wells reduced the distance children travelled to find water. When chores become easier, it is undoubtedly easier for boys to agree to do them. Engaging classroom materials and caring relations between teachers and children, along with toilets and water, were all valued and drew children to school.

Addressing gender disparities in school entailed attention to a wide range of issues that on the surface seem unrelated. The program staff understood the myriad influences that encourage and discourage children from attending school, including gendered issues such as the need for toilets and privacy for personal hygiene (Kirk \& Sommer 2006; Sommer, 2013). They also recognized local cultural knowledge and logic that situated girls' schooling as a community benefit. Strategies as diverse as providing a high quality educational experience, redistributing responsibility for chores, digging wells and building toilets, and creating structures of shared power over educational decisions were meaningful because they make sense in a larger and more complex sociocultural, economic, and environmental context. The 
intertwining elements of this program emerged out of these particular villages in a specific region, and is unlikely to be as successful if simply replicated in other contexts - programs should grow out of the particulars of the contexts in which they are situated.

\section{Infusing Gender}

Throughout these varied and intertwined influences we see a consistent prioritizing of gendered awareness. Girls' educational experience and gender equity are positively affected by having wells and toilets, which help to make school accessible to adolescent girls. Recruiting local teachers, many of whom are young women, helped to elevate women's and girls' status in communities: the young women teachers had high status jobs and became role models for younger girls. ECE deepens a sense that school is for everyone; it freed up older girls to attend school themselves, as their younger siblings (or children) are cared for in a safe and stimulating space, which also created an early habit of going to school. The gendered human rights frameworks that guide this NGO's work bring out more awareness of gendered social structures. This awareness evolved over time, sometimes unpredictably.

A long-time consultant with this NGO reflected in his interview on how a focus on gender became infused into the program:

So I think there were a number of things that happened in the project that were important - and because of this focus on girls [reflecting the funding parameters], one of the unexpected outcomes was that it actually raised the awareness of gender at the community level.

He went on to describe an early research project in two schools that had two classrooms for each grade: they separated boys and girls into separate classes. For one year there were single-sex classrooms for grades 1 and 2 . He continued:

[T] hen we looked at the academic achievement after 12 months in terms of math and language - and the outcome. It did show that girls were advantaged by singlesex classrooms. But what was really the best outcome of that little project, is that it really made the community school boards and teachers and parents start thinking about gender and girls and boys and education and what their needs might be in a way that they'd never done before. So it really raised the profile of gender at the community level, and I wasn't really expecting that - I thought, okay, we'd get academic achievement outcomes, but in fact, there was this other outcome which was much more important.

This realization informed the NGO's work in the villages and with local and regional governments, including the Women's Committees, to reflectively and critically examine, as the consultant stated, "the place and 
role of women in society, and what their plans were and what their vision was for the future." This is what led to the realization that the time it took girls to do their chores prevented them from attending school. The consultant explains:

[R]eally it was just about raising the level of awareness of the community, and getting them to make action plans of what they're going to do to achieve what their vision [is] for the place of girls and women in their community - it was an action-research model actually, though we never used that word.

Over the 10 years of this program, through the building of intentional and meaningful relationships in the villages, and informed by flexible conceptual frameworks and the preliminary research in the villages, this program came to recognize and re-think gender relations, fine-tuning and refocusing their guiding gender-related policy agenda. The NGO developed strategic relationships with other NGOs, a UN agency, and local government officials - they realized that this broader support structure would be necessary to sustain the work in the communities, and expand it to other villages. Educating girls was built on recognizing gender relations in communities (not merely counting girls in school), and working to make those social structures more equitable. Again, we see the intertwining of policy on multiple levels, practice, and research.

Recognizing gendered social structures can bring to view barriers to girls attending school and can also become a motivation to transform gendered social practices to address broader community concerns, whether school access, extending human rights to girls and women, or confronting rapidly changing socioeconomic and political conditions. The arguments for educating girls were not simplistic. Restructuring the household division of labor, for example, enabled girls to join boys in helping communities transition from subsistence farming to integrating additional and alternative means of income generation, and to engage in a critical politics related to land use, environmental degradation, and economic exploitation. Educating girls was not merely about meeting EFA goals and MDGs, but became an integral part of a multi-faceted approach to community survival.

\section{Meaningful Social Change through Education}

Across the multifaceted narratives about this girls' education program, and intertwined with the research-policy-practice nexus, we see four elements that seem integral to making discursive shifts from broad global policy priorities of access and parity, and sometimes quality, to highly contextualized and complex explanations about why girls should be educated. The four elements are space, time, funding, and conceptual underpinnings.

Space - physical, social, and curricular space especially - is where things happen. The NGO built early childhood centers in the villages; these are two- 
room buildings that house an early childhood classroom, and another room that can serve as a classroom or meeting space. Many of our focus groups met in these buildings or in the village meeting hall; the NGO also used these spaces in their work in villages. Physical spaces such as these enable social interaction and collective discussion in neutral locations about local priorities.

Social space for initiating, developing, and engaging in relationships was key to the NGO's work. They carefully yet strategically developed open, valued, and meaningful relationships with UNICEF, government entities from the national to the local levels, other NGOs, and people in the villages. They visited villages frequently, and responded to requests from the villages. These interactions are where social relations were built and managed, negotiated and deepened. They listened to local priorities and changed their own understandings of their concerns as they learned more. They also relied on sociopolitical structures already in place, such as the Women's Committees, engaging them as support conduits.

Curricular space is conceived here as space where knowledge is engaged, both in and outside of schools, in ways that alter thinking. The NGO's approach to working with communities was not rigid or bureaucratically imposed. Villagers recounted many stories about how children's and teachers' engagement with the curriculum in the schools promoted thinking differently about the structures that shape lives; recall the consultant's description of their action research approach. The substance or content of teaching and learning, and of broader engagement in communities, when it can take on a life of its own (e.g., evolve organically), is a curricular space where responsive, reflective and reflexive transformative processes occur. This takes time.

Time and space work hand in hand. The meaningful development of social relationships takes time, as does working through challenges such as listening to varying perspectives or resolving disagreements. This program was funded for 10 years, which enabled a more intentional process of engaging in informed and sustained change. The NGO staff had time to become deeply informed - to learn more about local life and national and regional politics, for example - and to engage communities in participatory approaches to change that were solidly grounded in village priorities and perspectives. When things needed to change, they had time to change them. Some staff were already well embedded in local communities. Others needed staff development so they could rethink their assumptions about ethnic relations and prejudices in this country. This is hard work that requires sustained engagement.

Funding to support programs such as this can constrain or enable creativity and adaptation. The funding was substantial, and came from a private donation. The strings attached to the funding were not rigid and encouraged innovation and locally-relevant flexibility in doing meaningful gender and education work. The same funder also funded several other countries' initiatives through the same NGO. Each of these programs developed in very 
different ways, demonstrating that context matters.

With funding cycles in development projects more typically three to five years, it was clear that having 10 years provided a much richer experience and one that saw a dramatic boost in school enrollments and attainment (thereby meeting global education policy priorities and targets such as EFA and the MDGs), while moving beyond them to make a difference in people's thinking, ways of learning, and lived experience.

Funding that is restrictive or prescriptive would likely not enable these kinds of outcomes. There are no shortcuts or silver bullets in doing development education work. This program's duration enabled a deeper basis for sustainability built on high levels of relevancy and integral local involvement. Funding that pays for results (UNESCO, 2017) (which is not the model followed in this program) would seem to constrain potential for deeply grounded change. Access and parity, when assessed as an outcome, may preclude their roles as necessary means toward bigger goals such as community sustainability.

Conceptual underpinnings, embodied in the NGO's frameworks and in the early research they did, also helped to inform and guide their work. These conceptual ideas were not translated into prescriptions for practice; they generated an authentic and dynamic internal dialogical process. Conceptual ideas that informed thinking and social change included a human rights orientation and an empowerment framework, an understanding of language acquisition and pedagogy (Benson \& Kosonen, 2013), and also an understanding of local culture, village priorities, and social structures related to politics, economics, and the environment. The critical orientation of this work enabled a program that was not constrained by narrow global policy goals (i.e., access and parity), but was responsive to changing understandings of local realities, open to considering broader (and more structural) conceptual ideas about gender and education, and able to evolve over time.

In conclusion, when time (enough time to adapt approaches along the way), funding (with limited strings attached), space (to enable valued social relations to develop), and conceptual ideas (that guide without being prescriptive) come together to enable dynamic engagement in addressing social problems and promoting social justice, we see meaningful change that has a good chance to grow and evolve after the program is formally over. While a few villages had ongoing or new challenges, overall we saw the confluence of these four elements in this region in ways that have changed people's thinking about gender relations, giving girls more chances to pursue a future that situates them as valued members of their communities.

\section{Conclusion}

Although it is the work done on the ground that makes a locally discernable difference, global policy is also important: it names the education of girls as a 
global priority, it likely helps attract funding, and provides some legitimacy to projects that prioritize gender. In addition, the reflective processes undertaken by the NGO internally (with staff) and with the villagers and their partners (including government entities) made their work responsive to both local villages' priorities and attractive to the state as they moved to take over after the program funding ended.

This work is not simplistic. Embracing complexity is necessary and can be difficult and unpredictable. Engaging gender as a social structure embedded in social relations and cultural meaning systems - not just counting bodies in seats - enables a richer understanding of gendered disparities in education, and a much more dynamic approach to moving toward gender equity. Participatory pedagogies enable this flexibility and dynamism.

When policy, research, and practice work together to inform how we think about development education and how we approach it, and when this nexus is overlaid by sufficient time, space, funding, and supportive conceptual ideas, we can more clearly (a) make changes to underlying inequitable gendered and other social structures, (b) meaningfully apply global policy agendas to local realities and priorities, and (c) situate educational practice in a wellinformed and policy guided (not rigidly dictated) context. In this paper we have tried to examine one initiative that was committed to think complexly through these kinds of interactions. While this program was not perfect, it demonstrates the value of active engagement in thinking deeply and doing critical and multifaceted work in educational practice, policy, and research.

\section{Acknowledgements}

This work could not have been done without the willingness of the participants to share openly their experience and perspectives. I deeply appreciate Shirley Miske for enabling my participation in this project designed to "tell the story" rather than impose a more traditional evaluation. Thank you to the two graduate students I worked with - Laura Wangsness Willemsen (now Dr. Willemsen) for her energy and insight during the data collection and initial analysis process, and Carmela Lopriore with her often astute observations as we worked through the data again. NGO work is so important and it was an honor to learn about this project from the ground up. DePaul University provided a research leave that freed up time for the development of this paper. I also am deeply grateful to Jackie Kirk's clear vision of what matters in our work, as that has served as a lasting inspiration.

\section{References}

Aikman, S. \& Unterhalter, E. (Eds.). (2005). Beyond access: Transforming policy and practice for gender equality in education. Oxford: Oxfam.

Studies in Social Justice, Volume 12, Issue 2, 195-214, 2018 
Aikman, S., Unterhalter, E., \& Challender, C. (2005). The education MDGs: Achieving gender equality through curriculum and pedagogy change. Gender \& Development, 13(1), 44-55.

Bajaj, M. (2011). Human rights education: Ideology, location, and approaches. Human Rights Quarterly, 33, 481-508.

Benson, C., \& Kosonen, K. (Eds.). (2013). Language issues in comparative education: Inclusive teaching and learning in non-dominant languages and cultures (pp. 283-301). Rotterdam: Sense Publishers.

Boserup, E. (1970). Woman's role in economic development. New York: St. Martin's Press.

Chisamya, G., DeJaeghere, J., Kendall, N., \& Khan, M.A. (2012). Gender and education for all: Progress and problems in achieving gender equity. International Journal of Educational Development, 32, 743-755.

Coysh, J. (2014). The dominant discourse of human rights education: A critique. Journal of Human Rights Practice, 6(1), 89-114.

Herz, B., \& Sperling, G. B. (2004). What works in girls' education: Evidence and policies from the developing world. New York: Council on Foreign Relations.

Kabeer, N. (1997) Reversed realities: Gender hierarchies in development thought. London: Verso.

Kendall, N. (2007). Education for all meets political democratization: Free primary education and the neoliberalization of the Malawian school and state. Comparative Education Review, 51(3), 281-305.

Kendall, N., \& Silver, R. (2014). The consequences of global mass education: Schooling, work, and well-being in EFA-era Malawi. In N. P. Stromquist \& K. Monkman (Eds.), Globalization and education: Integration and contestation across cultures ( $2^{\text {nd }} \mathrm{ed}$.) (pp. 247-265). Lanham, MD: Rowman \& Littlefield.

King, E. M., \& Hill, M. A. (Eds.). (1993). Women's education in developing countries: Barriers, benefits, and policies. Baltimore, MD: Johns Hopkins University Press.

Kirk, J. (2004). Impossible fictions: The lived experiences of women teachers in Karachi. Comparative Education Review, 48(4), 374-395.

Kirk, J. (2007). Gender-based violence in and around schools in conflict and humanitarian contexts. In T. Geraldine \& J. Hoare (Eds.), Gender-based violence (pp. 121-132). Oxford: Oxfam.

Kirk, J., \& Sommer, M. (2006). Menstruation and body awareness: Linking girls' health with girls' education. Amsterdam: Royal Tropical Institute (KIT).

Leach, F., \& Mitchell, C. (Eds.). (2006). Combating gender violence in and around schools. Stoke on Trent, UK: Trentham Books.

Levinson, B. A. U., Sutton, M., \& Winstead, T. (2009). Education policy as a practice of power: Theoretical tools, ethnographic methods, democractic options. Educational Policy, 23(6), 767-795.

Lewis, M. A., \& Lockheed, M. E. (2006). Inexcusable absence: Why 60 million girls still aren't in school and what to do about it. Washington DC: Center for Global Development.

Lorber J. (1994). Paradoxes of gender. New Haven, CT: Yale University Press.

McCormick, A. (2016). Policy constructions of childhoods: Impacts of multi-level education and development policy processes in Southeast Asia and the South Pacific. In L. Hopkins \& A. Sriprakash (Eds.), The 'poor child': The cultural politics of education, development and childhood (pp. 127-150). London: Routledge.

McIntosh, P. (2013). White privilege and male privilege: Unpacking the invisible knapsack. In M. L. Andersen \& P. Hill Collins (Eds.), Race, class, and gender: An anthology ( $8^{\text {th }}$ ed.). Belmont, CA: Wadsworth.

Mohanty, C. T. 2003. Feminism without borders: Decolonizing theory, practicing solidarity. Durham, NC: Duke University Press.

Molyneaux, K. J. (2011). Uganda's universal secondary education policy and its effect on 'empowered' women: How reduced income and moonlighting activities differentially impact male and female teachers. Research in Comparative and International Education, $6(1), 62-78$.

Monkman, K. (2011). Framing gender, education and empowerment. Research in Comparative \& International Education, 6(1), 1-13. 


\section{Karen Monkman}

Monkman, K. \& Hoffman, L. (2013). Girls' education: The power of policy discourse. Theory \& Research in Education, 11(1), 63-84.

Monkman, K., \& Webster, K. (2015). The transformative potential of global gender and education policy. In J. Zajda (Ed.), International handbook of globalisation, education and policy research ( $2^{\text {nd }}$ ed.) (pp. 467-484). Dordrecht: Springer.

Murphy-Graham, E. (2008). Opening the black box: Women's empowerment and innovative secondary education in Honduras. Gender \& Education, 20(1), 31-50.

Parkes, J. (2016). The evolution of policy enactment on gender-based violence in schools. Prospects, 46, 93-107.

Rossman, G. G., \& Rallis, S. F. (2003). Learning in the field ( $2^{\text {nd }}$ ed.). Thousand Oaks, CA: Sage.

Shah, P. P. (2011). Girls' education and discursive spaces for empowerment: Perspectives from rural India. Research in Comparative \& International Education, 6(1), 90-106.

Sommer, M. (2013). Structural factors influencing menstruating school girls' health and wellbeing in Tanzania. Compare: A Journal of Comparative and International Education, 43(3), 323-345.

Sutton, M. (1998). Girls' educational access and attainment. In N. P. Stromquist (Ed.), Women in the Third World: An encyclopedia of contemporary issues (pp. 381-396). New York: Garland.

UNESCO. (2018). Meeting our commitments to gender equality in education. Global education monitoring report gender review. Paris: UNESCO.

UNESCO. (2017). Accountability in education: Meeting our commitments. Global education monitoring report 2017/2018. Paris: UNESCO Publishing.

UNESCO. (2012). Reaching out-of-school children is crucial for development. Policy Paper 04, June. Education for All Global Monitoring Report and UNESCO Institute for Statistics. UNESCO, Paris.

UNICEF/Miske Witt Associates Inc. [MWAI] (2007). Transition to post-primary education with a special focus on girls. Nairobi: UNICEF.

Unterhalter, E., Heslop, J., \& Mamedu, A. (2013). Girls claiming education rights: Reflections on distribution, empowerment and gender justice in Northern Tanzania and Northern Nigeria. International Journal of Educational Development, 33, 566-575.

Unterhalter, E., \& North, A. (2011). Girls schooling, gender equity, and the global education and development agenda: Conceptual disconnections, political struggles, and the difficulties of practice. Feminist Formations, 23(3), 1-22.

Vavrus, F. (2002). Uncoupling the articulation between girls' education and tradition in Tanzania. Gender \& Education, 14(4), 367-389.

Vavrus, F. (2005). Adjusting inequality: Education and structural adjustment policies in Tanzania. Harvard Educational Review, 75(2), 174-201.

Zembylas, M. (2017). Re-contextualising human rights education: Some decolonial strategies and pedagogical/curricular possibilities. Pedagogy, Culture \& Society, 25(4), 487-499. 